\title{
Adverse Event Domain
}

National Cancer Institute

\section{Source}

National Cancer Institute. Adverse Event Domain. NCI Thesaurus. Code C49562.

A subject domain utilized for the submission of information encompassing and representing data, vocabulary or records related to an adverse event. 